\title{
Linear tracks and restricted temperature ranges characterise penguin foraging pathways
}

\author{
P. N. Trathan ${ }^{1, *}$, C. Bishop ${ }^{2}$, G. Maclean ${ }^{3}$, P. Brown ${ }^{3}$, A. Fleming ${ }^{1}$, M. A. Collins ${ }^{1}$ \\ ${ }^{1}$ British Antarctic Survey, High Cross, Madingley Road, Cambridge CB3 0ET, UK \\ ${ }^{2}$ School of Biological Sciences, University of Wales, Deiniol Road, Bangor LL57 2UW, UK \\ ${ }^{3}$ Navsys Ltd., Springwood House, Linburn Road, Kirknewton, Edinburgh EH27 8DY, UK
}

\begin{abstract}
Marine predators are thought to follow sophisticated scale-dependent search strategies when seeking patchy and unpredictable prey. However, fine-scale information about these strategies has hitherto been difficult to obtain for diving predators that often remain at the sea surface for only limited periods of time. Using ARGOS telemetry and novel, low-powered, archival GPS, we followed the fine-scale at-sea behaviour of king penguins breeding on South Georgia. Results revealed that foraging pathways were generally linear, except at the finest scale, where movements probably reflected either fine-scale searching behaviour, or fine-scale random movements associated with having found prey. King penguins focused $45 \%$ of their foraging effort in waters with a specific surface temperature $\left(5.0\right.$ to $\left.5.5^{\circ} \mathrm{C}\right)$ - an environmental cue potentially important in helping them locate prey, thereby reducing their need to expend energy in area-restricted search patterns. Within these waters, penguins slowed down and increased their dive effort and degree of meandering. First Passage Time analysis revealed that penguins focused much of their effort at local scales, generally in areas with a radius of $2 \mathrm{~km}$. In these areas, penguins dived marginally deeper and targeted waters that were significantly warmer at the bottom of their dives. Such information about fine-scale foraging behaviour will help increase our understanding of the environmental correlates that characterise areas where marine predators exploit their prey. The scale of these behavioural processes is better resolved using the fine-scale temporal and spatial resolution of GPS tracking data.
\end{abstract}

KEY WORDS: Foraging · GPS telemetry · Archival GPS · Environmental cues · King penguin · Diving predators · Antarctic Polar Front · South Georgia

- Resale or republication not permitted without written consent of the publisher

\section{INTRODUCTION}

In the marine environment, the predictability of patchily distributed prey is often scale dependent (Weimerskirch 2007). Thus, prey may be unpredictable at small spatial scales ( $\mathrm{m}$ to $\mathrm{km}$ ), while they may be more predictable at larger spatial scales (10s to $100 \mathrm{~s}$ of $\mathrm{km}$ ) characteristic of fronts, shelf edges and some meso-scale oceanographic features. As a consequence, marine predators are thought to utilise sophisticated search strategies in locating profitable food resources. However, understanding the foraging decisions made by free-ranging marine predators remains a challenge, as information about their movement patterns is largely unknown. Recent studies have used statistical descriptions of telemetry data or other empirical tracking data to elucidate how predators travel and search for prey (Viswanathan et al. 1996, Jonsen et al. 2003), or how they alter their search scale when they encounter rewarding prey aggregations (Fauchald 1999, Fauchald et al. 2000, Fauchald \& Tveraa 2003). Thus, foraging behaviour in the marine environment is generally scale dependent (Pinaud \& Weimerskirch 2005), and information at a variety of scales, including that of individual dives and prey patches, is critical in understanding how marine predators exploit their prey field.

Recently, Weimerskirch (2007) showed that marine predators do not search randomly. Using tracking data from flying seabirds, Weimerskirch (2007) suggested that seabirds have prior knowledge of the location and 
concentrations of prey patches at both large and mesoscales, and generally use a commuting type of trip to reach foraging zones. Consequently, food predictability appears to be high at large and meso-scales, with individuals heading in a particular direction to reach favoured regions of enhanced productivity such as those that occur at shelf edges, frontal zones, or upwelling areas. Weimerskirch (2007) further suggested that within these meso-scale features, marine predators switch to an area-restricted search strategy (Kareiva \& Odell 1987) in order to detect patches at finer scales, or better exploit aggregated prey.

Nevertheless, some foraging habitats are less predictable than others, particularly those in deep and offshore waters (Weimerskirch 2007). In such habitats, prey are often diffuse or occur at low levels of abundance (Hill et al. 2007). Consequently, optimal foragers may be highly reliant upon environmental cues that increase their ability to detect prey in these situations. In the open ocean, the spatial scales of foraging behaviour might therefore be expected to correlate with environmental features at a range of scales.

In this study, we look at the foraging behaviour of a key avian predator from the Sub-Antarctic region, the king penguin Aptenodytes patagonicus. King penguins forage in oceanic waters and spend little time searching; instead, they travel directly to feed in areas where there are strong environmental correlates (Jouventin et al. 1994). Interestingly, estimates of energy expenditure in king penguins (derived from heart rate loggers) suggest that travelling birds expend less energy than do actively foraging birds (Froget et al. 2004). This suggests that the fine-scale foraging activity of these penguins is a critical element of their behaviour at sea.

The specific objectives for this study were 2-fold: (1) to compare characteristics of penguin foraging behaviour derived from conventional ARGOS telemetry loggers with that from newly available GPS loggers; and (2) to determine whether measures of foraging behaviours (e.g. speed, dive depth, etc.) vary with environmental correlates at fine spatial and temporal resolution.

\section{MATERIALS AND METHODS}

Our study was carried out on South Georgia, a SubAntarctic island located within the eastward flow of the Antarctic Circumpolar Current. On South Georgia, the breeding population of king penguins is $>450000$ pairs (Saunders 2006). The study took place on the north coast of the island at Hound Bay $\left(54^{\circ} 23^{\prime} 31.56^{\prime \prime} \mathrm{S}\right.$, $\left.36^{\circ} 15^{\prime} 15.84^{\prime \prime} \mathrm{W}\right)$ between late December 2005 and early January 2006. This period coincides with the incubation phase of king penguins. Individuals were se- lected in the colony and marked with coloured organic hair dye. Marked birds were then captured after they had left the colony but before they entered the sea to undertake their long post-laying foraging trips. All deployments were made on breeding females.

After birds returned from their foraging trips, all tags were recovered and data were downloaded and archived for subsequent analysis. Analyses of ARGOS, GPS and time-depth recorder (TDR) data were carried out in Matlab 7.1 (Mathworks) using custom-developed software scripts. Statistical tests were also carried out in Matlab, although additional regression analyses were carried out in R 2.3.1 (R Core Development Team).

Tracking data. We used 2 forms of satellite tracking devices: (1) SPOT 4 ARGOS Platform Terminal Transmitters (PTT) (Wildlife Computers) configured with a transmission repetition rate of $45 \mathrm{~s}$ and equipped with a saltwater switch to delay transmission while birds were under water (PTTs weighed 70 g, i.e. $<0.5 \%$ of body mass, and measured $25 \times 90 \times 10 \mathrm{~mm}$, i.e $<0.5 \%$ of the cross sectional area of the body); and (2) TrackTag $^{\mathrm{TM}}$ GPS loggers (Navsys) that require only $60 \mathrm{~ms}$ to store raw GPS data to non-volatile memory (sufficient for 32750 positions) for subsequent post-processing; if individuals are out of satellite view for prolonged periods, a position can still be calculated from the next snapshot (see Schofield et al. 2007). These devices make no onboard computation of position; compared with the onboard computation and slower acquisition rates of the GPS devices used by Weimerskirch et al. (2002) and Petersen et al. (2006), these devices defer computation of position, thereby reducing battery consumption by 100 -fold. Devices were programmed to record positions at $60 \mathrm{~s}$ intervals, and were equipped with a saltwater switch to delay acquisition while birds were under water. Loggers, with batteries and housing (tested to $400 \mathrm{~m})$, weighed $55 \mathrm{~g}(<0.5 \%$ of body mass) and measured $35 \times 100 \times 15 \mathrm{~mm}(<0.7 \%$ of the cross sectional area of the body). Further details of TrackTag $^{\mathrm{TM}}$ are available at www.navsys.com/Products/ tracktag.htm. Use of this novel GPS tracking device allows the finest scales of foraging to be studied, which is not possible with conventional ARGOS telemetry.

In addition to the horizontal tracking devices, all birds were equipped with Mk9 TDRs with external temperature sensors on a stalk to permit a rapid temperature response (Wildlife Computers). These were programmed to record depth at $1 \mathrm{~s}$ intervals. TDRs weighed $30 \mathrm{~g}(<0.25 \%$ of body mass $)$ and measured $15 \times 100 \times 15 \mathrm{~mm}(<0.5 \%$ of the cross sectional area of the body). Eleven birds were equipped with PTTs and TDRs, and 4 birds with GPS and TDRs. Devices were attached using methods modified from previous researchers (Wilson et al. 1997). 
Analysis of tracking data. ARGOS tracking data were filtered to remove positions where travel speeds exceeded $14 \mathrm{~km} \mathrm{~h}^{-1}$ (Kooyman \& Davis 1987). This largely removed positions of lower quality $(1.15 \%$ of positions) (see www.argos-system.org/html/system/ faq_en.html\#LOCATION\%20ACCURACY for details of location quality).

GPS tracking data were filtered to remove positions with navigation class $>2$, where class categories were 0: good, 1: altitude aided, 2: marginal Position Dilution of Precision (>6), and 3: bad. The average minimum accuracy of positions (given by 2dRMS) was $29.28 \mathrm{~m}$, estimated using 14000 consecutive positions collected from a horizontal and stationary logger (see www. fs.fed.us/database/gps/mtdc/gps2000/gps_comparison. htm for details of 2dRMS).

As the GPS data were more accurate and more frequent, we used the foraging tracks of the GPS tracked birds to determine both travel speed and the degree of meandering in the foraging path. When birds undertake area-restricted search patterns to locate prey, more tortuous foraging tracks should be evident and the degree of meandering should increase. We therefore employed a commonly used descriptor of meandering known as the straightness index, which is calculated as the direct distance travelled divided by the cumulative distance travelled (point to point) along the foraging path; at unity, this index reflects a straight-line course. This index works well for oriented search paths such as penguin foraging tracks (Benhamou 2004).

A further index of foraging intensity is First Passage Time (FPT) (Fauchald \& Tveraa 2003). We calculated this for all birds (both ARGOS and GPS tracked birds) at spatial scales of radius $1,2,4,8,16,32,64$ and $128 \mathrm{~km}$. The relative variance in FPT $[S(r)]$ for points along the path will increase with increasing radius. Fauchald \& Tveraa (2003) denote this variance by $S(r)$ and measure it by $\operatorname{Var}[\log t(r)]$, where $r$ is the radius of the circle, and $t(r)$ is the time lag between the first-passage time forward and the first-passage time backward; $t(r)$ is log-transformed to make $S(r)$ independent of the magnitude of the mean FPT. When $r$ increases beyond the spatial scale of the intensively searched area, the relative difference in $t(r)$ between points within and outside the area will decrease, resulting in a decrease in $S(r)$. Whenever the search effort is clustered within a certain area, a maximum $S(r)$ should result, with $r$ corresponding to the spatial scale of the intensively searched area. However, the ability to measure the scale of the search pattern will depend on the resolution of the data used. To estimate FPT, we therefore interpolated foraging tracks at a temporal resolution of $5 \mathrm{~min}$, and then filtered the track to remove those positions where the radius at a given spatial scale overlapped with either the start or end of the foraging track or the colony location.
Additional descriptors of foraging activity were also determined from the TDR data, including estimates of maximum dive depth $(\mathrm{m})$, dive duration $(\mathrm{s})$, duration of the bottom period when the penguin was between 75 and $100 \%$ of the maximum depth (s), and dive rate (dives $\mathrm{h}^{-1}$ ). Dives were classified as either foraging dives (those $>20 \mathrm{~m}$; Pütz et al. 1998) or travelling dives depending upon dive depth.

Oceanographic data. A description of the extant environmental conditions within the study area was developed using sea-surface temperature (SST) data from the NASA MODIS satellite Aqua (http://modis. gsfc.nasa.gov). SST data were collated to form a single composite image for January 2006. The composite was created by producing a mosaic of all available SST data. Where multiple values were present for the same location, the arithmetic mean was inserted as the pixel value. Data were available at a pixel size of $0.0417 \mathrm{de}-$ grees of latitude $(\sim 4.6 \mathrm{~km})$.

Statistics. Statistical tests were undertaken to determine whether different behavioural characteristics were evident during different periods of foraging. As foraging tracks and associated behavioural characteristics are likely to be serially auto-correlated, nonparametric analysis was used. Thus, to determine how behavioural properties varied with SST, a KruskalWallis analysis of variance was carried out. For this, SST along the track was classified as a factor $(10 \times$ $0.5^{\circ} \mathrm{C}$ bins), while the various behavioural properties were averaged (or summed) over $1 \mathrm{~h}$ periods. Behavioural data were integrated over these $1 \mathrm{~h}$ intervals so that behavioural descriptors were only dependent upon local context, and estimates of behaviour were comparable to the spatial scale of the SST data.

To establish whether the time spent at different positions along the foraging pathway was linked with other behavioural characteristics, a stepwise generalised linear regression model was used. In this analysis, the dependent variable was the time spent in a locality, represented by travel speed. The candidate independent variables included in the model were SST, time of day, straightness index, dive rate, dive duration, maximum dive depth and duration of the bottom period. Data were integrated over $1 \mathrm{~h}$ intervals so that behavioural descriptors were only dependent upon local context, and estimates of behaviour were comparable to the spatial scale of the SST data. The final model was selected using Akaike's Information Criterion (AIC).

\section{RESULTS}

The average foraging trip duration was $18.56 \mathrm{~d}$ $( \pm 1.76 \mathrm{SD}$; all subsequent means are accompanied by 
SDs) for the 11 ARGOS tracked birds (0.27 ARGOS positions $\mathrm{h}^{-1}$ on average) and $19.64 \pm 2.74 \mathrm{~d}$ for the 4 GPS tracked birds (15.05 GPS positions $\mathrm{h}^{-1}$ on average). In comparison, the average trip duration was $18.24 \pm 2.06 \mathrm{~d}$ for 15 control birds (with no instruments), with the longest duration being $21.33 \mathrm{~d}$. The differences in trip duration were not significantly different between instrumented and control birds (2-sample $t$-test: $t=1.16 ; \mathrm{df}=14, \mathrm{p}>0.05)$.

All instrumented birds travelled northwards to the southern edge of the Antarctic Polar Frontal Zone (PFZ) (Fig. 1), here defined as the location where surface temperatures rapidly increase above $3.0^{\circ} \mathrm{C}$ (see Trathan et al. 1997 for surface temperatures at this time of year). The travelling speeds of ARGOS tracked birds ranged between 1.05 and $11.95 \mathrm{~km} \mathrm{~h}^{-1}$ (5 and $95 \%$ quantiles, respectively), with an overall mean of $5.25 \pm 3.34 \mathrm{~km} \mathrm{~h}^{-1}$. In comparison, the hourly mean travelling speeds of GPS tracked birds ranged between 0.59 and $6.04 \mathrm{~km} \mathrm{~h}^{-1}$ (5 and 95\% quantiles, respectively), with an overall mean of $4.32 \pm 2.11 \mathrm{~km}$ $\mathrm{h}^{-1}$. The observed difference in the upper range of these speeds could be due to differences in spatial accuracy. ARGOS tracking is potentially of much lower spatial accuracy since consecutive positions that occur

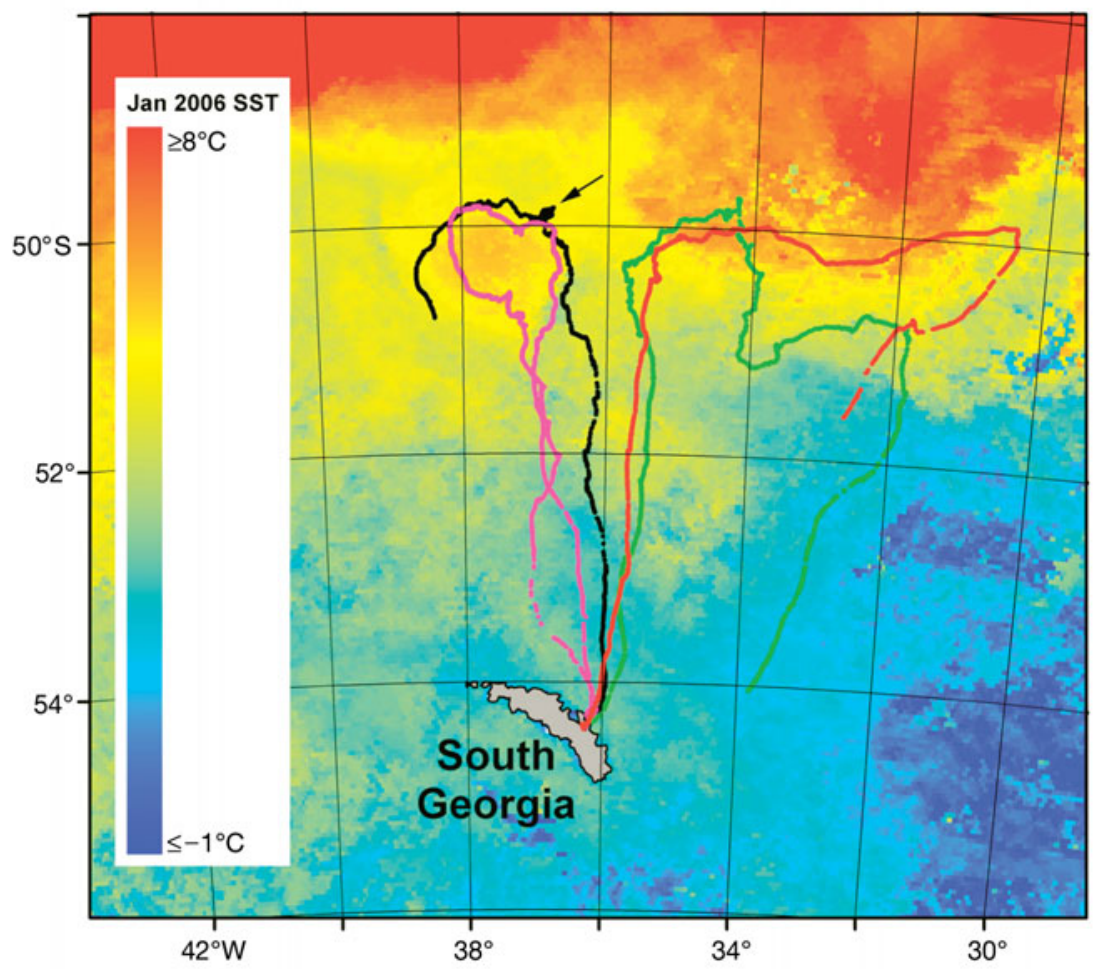

Fig. 1. Aptenodytes patagonicus. Foraging paths of 4 females fitted with archival GPS receivers. Also shown are sea surface temperature (SST) data from the NASA MODIS satellite Aqua (http://modis.gsfc.nasa.gov) collated to form a single composite image for January 2006. Black arrow indicates the detailed foraging paths shown in Fig. 3b close together in time, but which have low spatial accuracy, may potentially produce high apparent travel speeds. Thus, as GPS derived estimates of speed are potentially more accurate than ARGOS derived estimates due to the former's greater frequency of positions, all speeds are subsequently reported for GPS tracked birds only.

While commuting, birds travelled more than $80 \mathrm{~km}$ $\mathrm{d}^{-1}$ (direct distance midnight to midnight). However, they travelled shorter distances (only $23 \mathrm{~km} \mathrm{~d}^{-1}$ ) and remained within more restricted areas while in the PFZ. During their northward commuting period, birds travelled faster $\left(5.24 \pm 1.49 \mathrm{~km} \mathrm{~h}^{-1}\right)$, but slowed significantly (2-sample $t$-test: $t=17.06 ; \mathrm{df}=1543, \mathrm{p}<0.001)$ when within the PFZ (3.88 $\left.\pm 1.38 \mathrm{~km} \mathrm{~h}^{-1}\right)$ (Fig. 2). Generally, birds travelled at similar speeds (2-sample $t$-test: $t=$ $0.19 ; \mathrm{df}=1543, \mathrm{p}>0.05)$ during the day $(4.33 \pm 2.02 \mathrm{~km}$ $\mathrm{h}^{-1}$ ) and at night $\left(4.31 \pm 2.39 \mathrm{~km} \mathrm{~h}^{-1}\right)$ (Fig. 2). Paired $t$-tests (based on average speeds per bird) also showed similar speeds during the day and at night, both south of the PFZ (paired $t$-test: $t=0.48 ; \mathrm{df}=3, \mathrm{p}>0.05$ ) and within the PFZ (paired $t$-test: $t=0.43 ; \mathrm{df}=3, \mathrm{p}>0.05$ ).

The straightness index of the foraging track was used to identify the locations where foraging hotspots potentially occurred. As GPS derived estimates of position are likely to be more accurate than ARGOS derived estimates, straightness index values are here reported for GPS tracked birds only. For these birds, the straightness index remained high (close to unity) in the cooler waters to the south of the study area and decreased in the warmer waters to the north. This effectively corresponded to the commuting and focal foraging components of the foraging trip. Thus, the straightness index showed that birds followed relatively straight pathways $(0.76 \pm$ 0.17 ) while commuting, but followed more tortuous foraging pathways on reaching the PFZ as indicated by significantly decreased straightness index $(0.66 \pm 0.20)(2$-sample $t$-test: $t=9.72$; $\mathrm{df}=1543, \mathrm{p}<0.001)$. Most periods of meandering (defined as those within the lower quartile of straightness index values) therefore occurred while birds were in the warmer waters of the PFZ. Indeed, the longest recorded duration for any meandering period was just over $3 \mathrm{~d}$ and this occurred in the warmer waters of the PFZ (Fig. 3). In general, the straightness index showed a significant relationship with SST (Kruskal-Wallis: $\chi_{(9,1523)}^{2}=188.63 ; \mathrm{p}<$ 

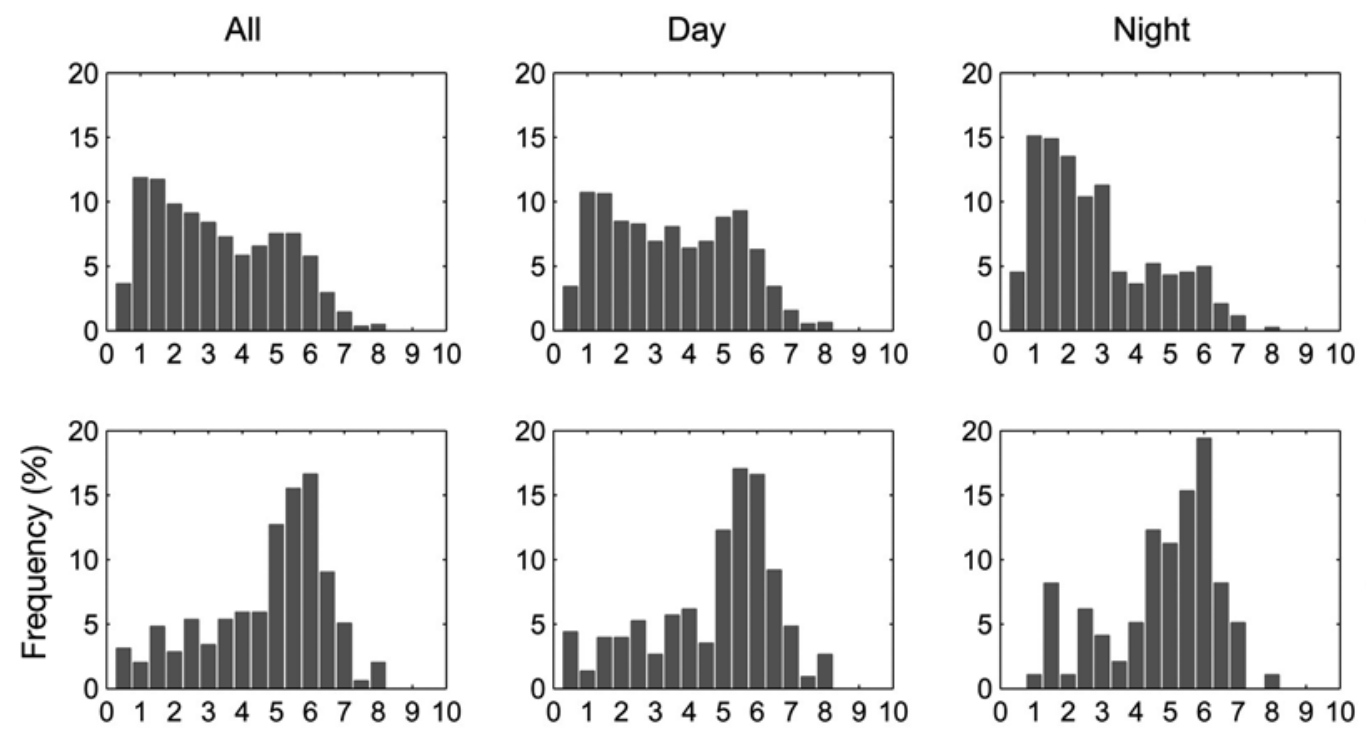

AAZ
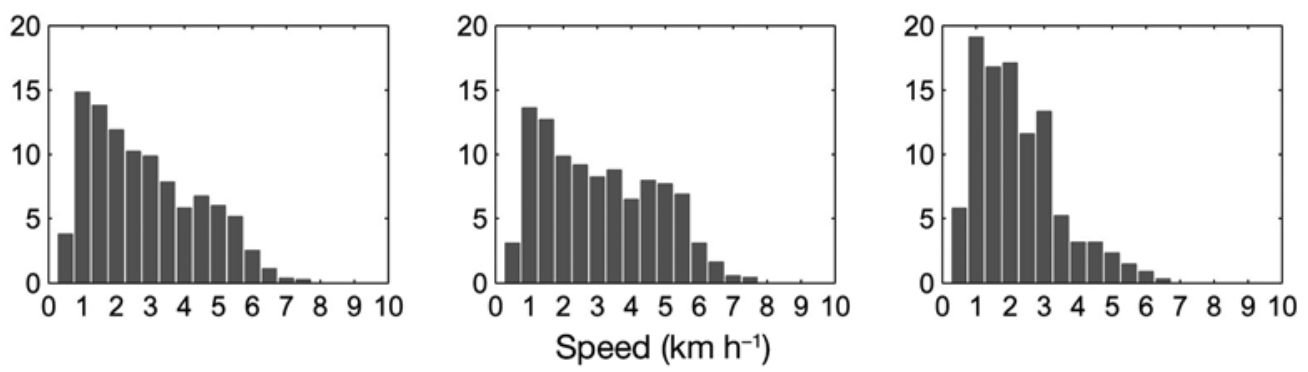

PFZ

Fig. 2. Aptenodytes patagonicus. Travel speeds throughout the foraging trip for all GPS tracked birds (All), birds in Antarctic Zone waters (AAZ), and birds in the Polar Frontal Zone (PFZ). Separate histograms for day and night travel are also shown

0.001), with lower straightness index values indicating more tortuous foraging tracks, in waters of $\sim 5.0$ to $5.5^{\circ} \mathrm{C}$.

Penguins dived throughout the day and night, with daytime dives being more frequent $(14.40 \pm 21.61$ vs. $10.62 \pm 16.94$ dives $\left.\mathrm{h}^{-1}\right)(2$-sample $t$-test: $t=3.47 ; \mathrm{df}=$ 1557, $\mathrm{p}<0.001)$. Average dive depth increased during daylight hours $(85.31 \pm 56.47$ vs. $26.38 \pm 30.86 \mathrm{~m})$ (2-sample $t$-test: $t=18.04 ; \mathrm{df}=1557, \mathrm{p}<0.001)$, as did dive duration $(189.90 \pm 89.41$ vs. $94.97 \pm 81.64 \mathrm{~s})$ (2-sample $t$-test: $t=16.94 ; \mathrm{df}=1557, \mathrm{p}<0.001)$. At night, birds dived less frequently and to shallower depths. This meant that they were at the surface for a greater proportion of time and in view of GPS satellites longer, thereby potentially increasing the number of GPS positions recorded at night. Nevertheless, the meandering index still showed a similar and significant relationship with SST both during the day (KruskalWallis: $\left.\chi_{(9,1023)}^{2}=136.80 ; \mathrm{p}<0.001\right)$ and at night (Kruskal-Wallis: $\chi_{(9,503)}^{2}=65.07$; $\left.\mathrm{p}<0.001\right)$.

Penguins dived during both the commuting period and the time that they were in the PFZ. While in the PFZ, penguins spent over $45 \%$ of their time in waters

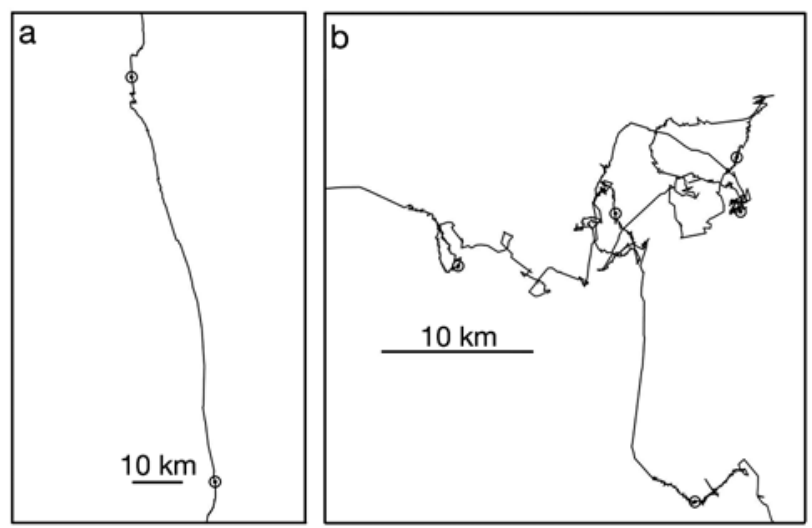

Fig. 3. Aptenodytes patagonicus. Detailed foraging track of GPS tracked birds showing (a) detailed section of outward travel, and (b) detailed area-restricted movement over $3 \mathrm{~d}$. Circles indicate local midnight

with surface temperatures of $\sim 5.0$ to $5.5^{\circ} \mathrm{C}$, significantly slowed their travel speed (Kruskal-Wallis: $\left.\chi^{2}{ }_{(9,1523)}=385.75 ; \mathrm{p}<0.001\right)$, increased their maximum dive depth (Kruskal-Wallis: $\chi^{2}{ }_{(9,1523)}=84.37$; $<<0.001$ ), 
and their dive duration (Kruskal-Wallis: $\chi_{(9,1523)}^{2}=$ $115.09 ; \mathrm{p}<0.001)$. In waters of 5.0 to $5.5^{\circ} \mathrm{C}$, penguins also decreased their dive rate (Kruskal-Wallis: $\left.\chi^{2}{ }_{(9,1523)}=199.26 ; \mathrm{p}<0.001\right)$.

Analysis of FPT for both ARGOS tracked and GPS tracked penguins showed similar results (Fig. 4). Most variance was apparent at small spatial scales, i.e. scales with radii between 2 and $16 \mathrm{~km}$. Only one GPS bird showed a FPT curve where the greatest variance occurred at $16 \mathrm{~km}$; this bird undertook the extensive period of area-restricted search shown in Fig. 3b. The majority of the FPT variances that fell within the upper quantile (i.e. the longest and slowest FPT) occurred in the PFZ, mainly north of $51^{\circ} \mathrm{S}$ (Fig. 5) (ARGOS: $83.10 \%$, GPS: $93.85 \%$ ), with many also north of $50^{\circ} \mathrm{S}$ (ARGOS: $53.54 \%$, GPS: $20.0 \%$ ). The pattern observed was evident during both day and night, suggesting that birds forage at characteristic scales that are only a few kilometres in area. Henceforth, we refer to these locations as 'FPT hotspots'.

The ARGOS FPT hotspots are dependent upon positional data with lower temporal resolution (ARGOS: $3.70 \pm 3.78 \mathrm{~h}$ between positions; GPS: $0.07 \pm 0.01 \mathrm{~h}$ between positions) and are thus spatially less precise than the GPS FPT hotspots. Hence, distances travelled between consecutive ARGOS positions (mean travel speed $\times$ mean position frequency $=15.98 \mathrm{~km}$ travelled between positions) are such that behaviour at scales finer than this will be smoothed spatially and temporally. Since GPS FPT hot- spots can be spatially resolved with greater accuracy, we used them to determine whether there were differences between dives undertaken within the FPT hotspots and dives undertaken outside such areas. Characteristics of foraging dives (dives $>20 \mathrm{~m}$ ) within and outside the FPT hotspots are presented in Table 1. Results show that more dives were carried out and that dives were marginally deeper inside the FTP hotspots. Our analyses also indicate that temperatures at the bottom of dives were significantly different within a FPT hotspot compared to dives outside. Bottom temperatures averaged $2.26^{\circ} \mathrm{C}, \sim 0.25^{\circ} \mathrm{C}$ warmer in the FTP hotspots than outside. Similarly, temperatures just

Table 1. Aptenodytes patagonicus. Foraging characteristics for dives $>20 \mathrm{~m}$ in areas where the First Passage Time (FPT) fell within the upper quantile of values (FPT hotspots) for the $2 \mathrm{~km}$ radius FPT analyses, compared with foraging characteristics from an equivalent number of randomly selected FPT areas. Depth, temperature and light data were taken from time-depth recorders (TDRs). $\mathrm{df}=9144$ for all entries

\begin{tabular}{|c|c|c|c|c|}
\hline \multirow{2}{*}{$\begin{array}{l}\text { FPT hotspot duration } \\
\geq 0.75 \text { quantile }\end{array}$} & \multicolumn{2}{|c|}{ FTP hotspots } & \multirow{2}{*}{$\begin{array}{c}t- \\
\text { value }\end{array}$} & \multirow[t]{2}{*}{$\mathrm{p}$} \\
\hline & ARS & ARS & & \\
\hline Daytime (06:00 to $22: 00 \mathrm{~h})(\%)$ & 60.79 & 67.95 & & \\
\hline Mean hotspot duration (min) & 291.60 & 90.63 & 90.73 & $<0.001$ \\
\hline Mean no. of dives per hotspot & 17.15 & 8.39 & 28.92 & $<0.001$ \\
\hline Mean max. dive depth $(\mathrm{m})$ & 109.28 & 105.65 & 3.06 & $<0.005$ \\
\hline Mean dive duration (s) & 236.46 & 245.79 & 8.26 & $<0.001$ \\
\hline Mean no. of undulations per dive & 11.05 & 11.17 & 1.11 & $<0.268$ \\
\hline Mean light at max. depth ${ }^{\mathrm{a}}$ & 0.40 & 0.42 & 7.91 & $<0.001$ \\
\hline Mean temp. at max. depth $\left({ }^{\circ} \mathrm{C}\right)$ & 2.26 & 1.98 & 10.10 & $<0.001$ \\
\hline Mean temp. at min. depth $\left({ }^{\circ} \mathrm{C}\right)$ & 5.00 & 4.01 & 32.91 & $<0.001$ \\
\hline
\end{tabular}

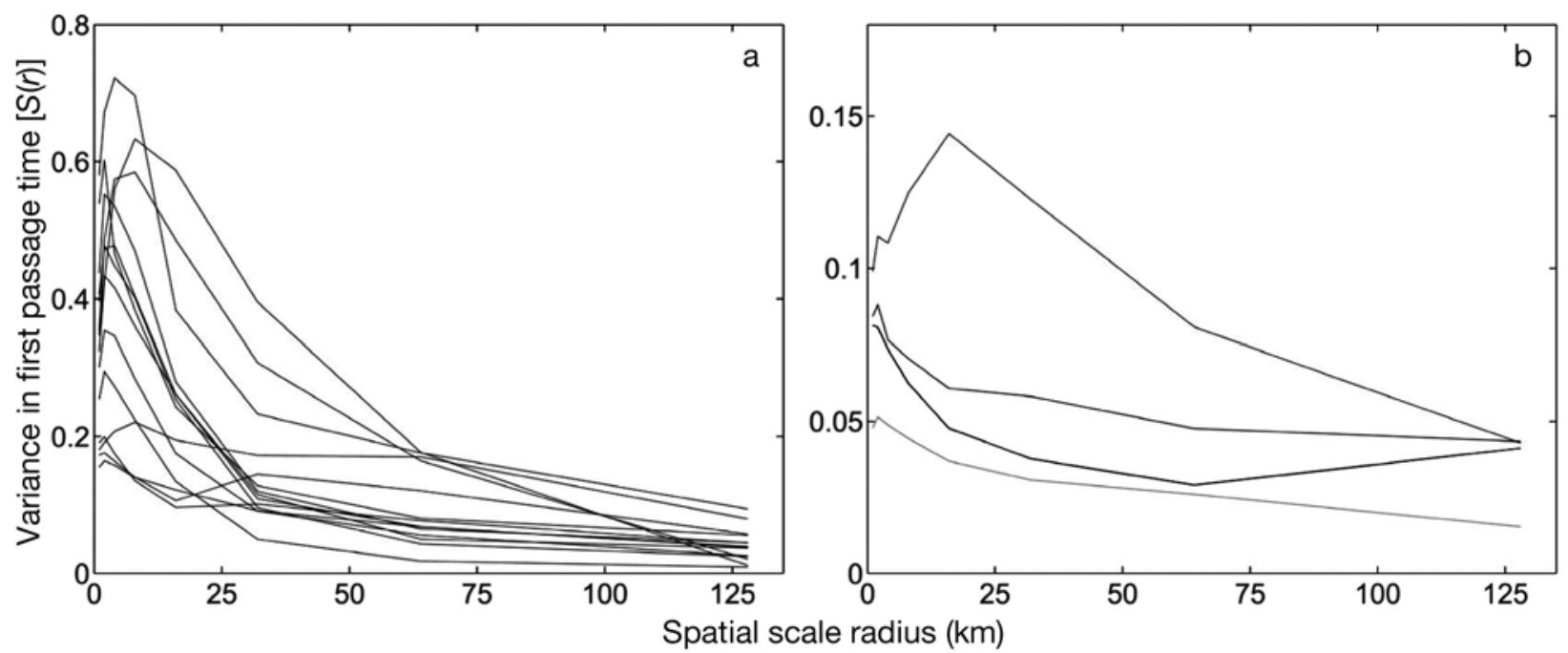

Fig. 4. Aptenodytes patagonicus. First Passage Time $[S(r)]$ for (a) ARGOS tracked birds, and (b) GPS tracked birds, after Fauchald \& Tveraa (2003). $S(r)=\operatorname{Var}[\log t(r)]$ where $r$ is the radius of the circle and $t(r)$ is the time lag in the first passage time. $t(r)$ is log-transformed to make $S(r)$ independent of the magnitude of the first passage time 


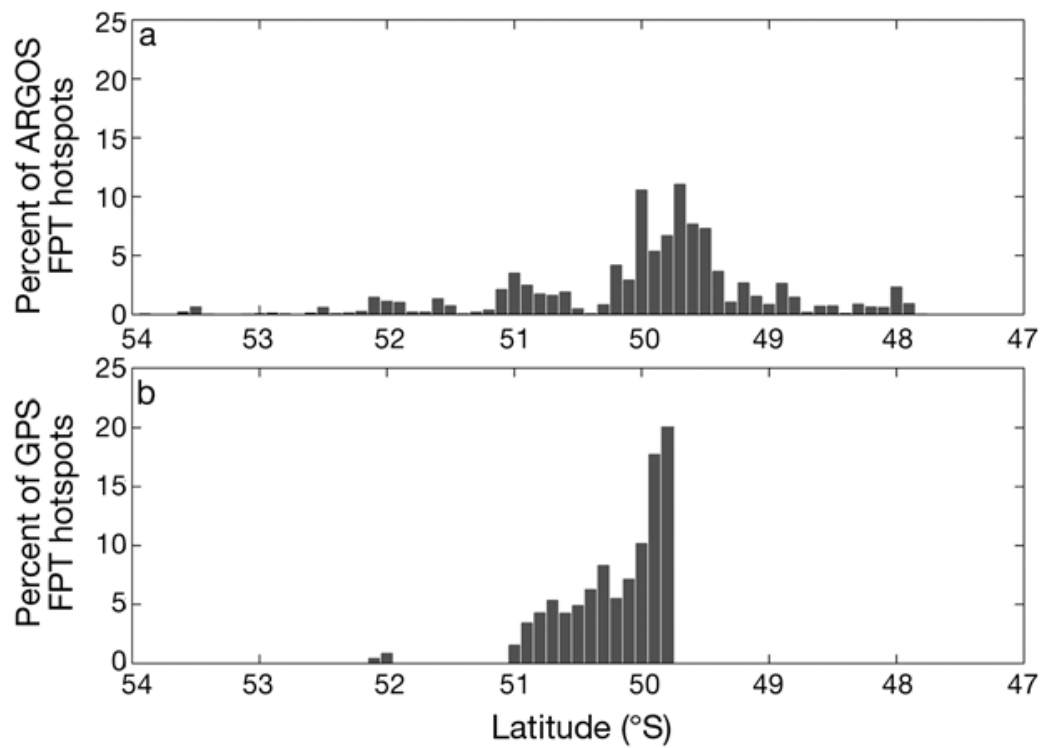

Fig. 5. Aptenodytes patagonicus. Latitudinal distribution of First Passage Time (FPT) hotspots (upper 0.75 quantile, i.e. the longest and slowest FPT) for (a) ARGOS tracked, and (b) GPS tracked birds

Table 2. Aptenodytes patagonicus. Generalised linear regression of travel speed on (Model 1) straightness index, latitude and maximum dive depth, and (Model 2) straightness index, sea-surface temperature (SST) and maximum dive depth. $\mathrm{p}<0.001$ for all entries. AIC: Akaike's Information Criterion

\begin{tabular}{|lrrr|}
\hline Coefficient & Value & SE & $t$-value \\
\hline Model 1 & & & \\
$\quad$ Intercept & -24.820 & 1.356 & -18.303 \\
Straightness index & 4.926 & 0.155 & 31.722 \\
Latitude & -0.487 & 0.027 & -18.144 \\
Max. dive depth & -0.004 & 0.001 & -6.964 \\
Null deviance & 4094.808 & & \\
Residual deviance & 1616.255 & AIC & 3874 \\
Model 2 & & & \\
Intercept & 1.447 & 0.179 & 8.106 \\
Straightness index & 5.228 & 0.160 & 32.674 \\
SST & -0.364 & 0.027 & -13.679 \\
Max. dive depth & -0.005 & 0.001 & -7.620 \\
Null deviance & 4064.055 & & \\
Residual deviance & 1749.052 & AIC & 3964 \\
\hline
\end{tabular}

below the water surface were significantly different, being $\sim 1^{\circ} \mathrm{C}$ warmer. SSTs inside the FTP hotspots $\left(5^{\circ} \mathrm{C}\right)$ also showed similarity with values recorded from satellites. The GPS FPT hotspots overlaid with SST values are shown in Fig. 6.

Stepwise, generalised linear regression showed that time spent within a location (expressed as travel speed) along the foraging pathway was significantly linked with other behavioural characteristics (Table 2). The independent variables finally selected in the model were the straightness index, latitude, and maximum dive depth; this model explained $60.53 \%$ of the deviations, indicating that the foraging path can be described by relatively simple behavioural characteristics. The model was similar in explanatory power to a second model with a similar AIC value. The independent variables in the second model were the straightness index, temperature, and maximum dive depth, which explained $56.96 \%$ of the deviations. As latitude and temperature are closely related (ANOVA: $F_{(1,1539)}=3918 ; \mathrm{p}<0.001, \mathrm{R}^{2}=$ $71.80 \%$ ), the similarity of the 2 models is not surprising.

\section{DISCUSSION}

Our study shows that king penguins use environmental cues as part of their larger spatial scale foraging behaviour. This was evident with both ARGOS and GPS tracking methodologies, although ARGOS results were more limited. Results indicate that many aspects of king penguin foraging behaviour can be adequately resolved using ARGOS telemetry; however, behaviour at the finest scale $(<16 \mathrm{~km})$ requires better-resolution spatial information such as is only currently available with GPS telemetry. At this fine scale, penguin foraging shows strong association with waters of a specific surface temperature $\left(\sim 5.0^{\circ}\right.$ to $\left.5.5^{\circ} \mathrm{C}\right)$, presumably characteristic of the environment where their main prey occur.

All study birds travelled directly north to the PFZ and a region characterised by high-energy oceanography and predictable meso-scale hydrographic features (Trathan et al. 1997, Arhan et al. 2002). During their journey northwards, penguins travelled rapidly and did not remain within a fixed locality for any extended period. Birds followed relatively straight pathways that were characterised by a low rate of meandering. However, despite the directional nature of their commuting, penguins dived repeatedly throughout their journey, a result also shown by Pütz et al. (1998). Since birds travelled northwards, the straightness of the foraging pathways supports the suggestion that they most likely use prior knowledge of the prey field (Weimerskirch 2007).

Within the PFZ, penguins slowed their rate of travel (Pütz et al. 1998). The circulation and movement of waters in the PFZ is complex and variable, and nearsurface currents flow at between 0.22 and $0.94 \mathrm{~km} \mathrm{~h}^{-1}$ (Trathan et al. 1997); consequently, the minimum 
$40^{\circ} \mathrm{W}$ $35^{\circ}$

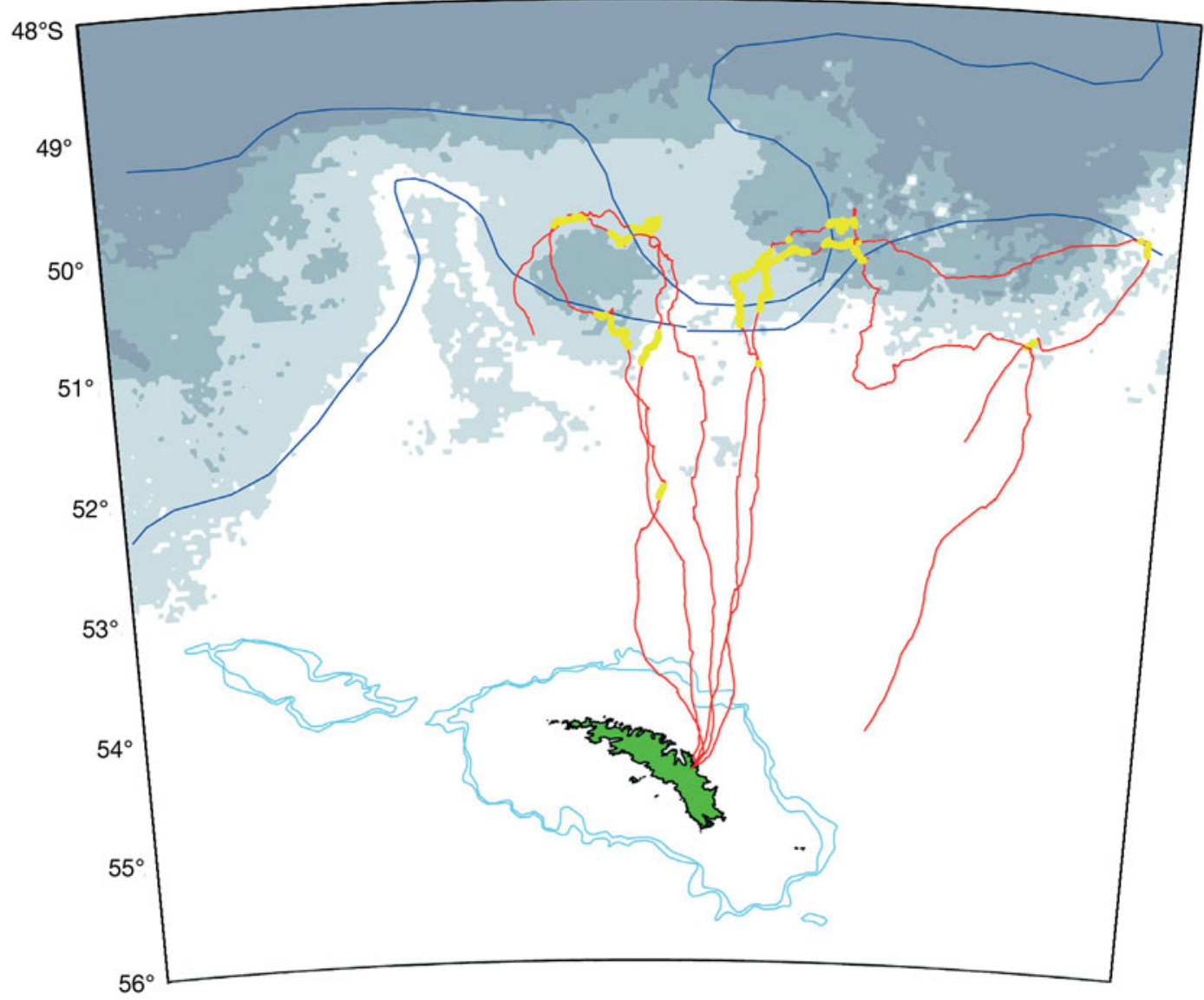

Fig. 6. Aptenodytes patagonicus. Spatial distribution of First Passage Time (FPT) hotspots (upper 0.75 quantile, i.e. the longest and slowest FPT) overlaid on sea-surface temperature (SST) for GPS-tracked birds. FPT hotspots are coloured yellow. SST is highlighted such that $\mathrm{SST}<5.0^{\circ} \mathrm{C}$ is shaded white, $\mathrm{SST}>5.0^{\circ} \mathrm{C}$ is shaded light grey, $\mathrm{SST}>5.5^{\circ} \mathrm{C}$ is shaded mid grey, and $\mathrm{SST}>$ $6.0^{\circ} \mathrm{C}$ is shaded dark grey. The 1000 and $2000 \mathrm{~m}$ isobaths (the solid pale blue lines) are shown as are the positions of the Antarctic Polar Front (the more southerly solid dark blue line) (after Trathan et al. 1997) and the Sub-Antarctic Front (the more northerly solid dark blue line) (after Orsi et al. 1995)

speeds that we observed $\left(0.59 \mathrm{~km} \mathrm{~h}^{-1}\right)$ suggest that birds may passively drift over some periods, particularly during the night.

Two GPS tracked penguins independently encountered the same circular meso-scale, warm-water feature in the PFZ, apparently following a temperature contour or a particular temperature discontinuity at the edge of this core-ring. Similar behaviour has also recently been reported by Cotté et al. (2007) and similar-scale hydrographic features have been recorded at nearby locations in the past (Trathan et al. 1997). It is thus likely that such features are highly predictable in this region. The fact that penguins target environmental cues such as water temperature or temperature gradients is potentially critical in predicting habitat use (Jouventin et al. 1994, Charrassin et al. 2004, Sokolov et al. 2006, Cotté et al. 2007).

The importance of temperature is further emphasised as GPS tracked penguins spent over $45 \%$ of their time in waters with surface temperatures of $\sim 5.0$ to $5.5^{\circ} \mathrm{C}$ at which they significantly slowed their rate of travel but increased their degree of meandering, maximum dive depth, dive duration, and the duration of time that they were at the bottom of their dives. Penguins presumably increased their dive effort and preferentially prolonged their stay at these temperatures as a consequence of an increased probability of encountering their main prey species, lantern fish (Myctophidae). Further work to understand the biogeography of Sub-Antarctic myctophid species is now necessary in order to fully understand this relationship. Early indications from such efforts suggest that at least some species do increase in biomass close to the $5.0^{\circ} \mathrm{C}$ surface isotherm (M. A. Collins et al. unpubl.).

King penguins can dive to depths $>250 \mathrm{~m}$ in search of lantern fish (Pütz et al. 1998); Krefftichthys anderssoni, Electrona carlsbergi and Protomyctophum choriodon dominate their diet, both in numbers and by mass 
(Olsson \& North 1997). These species generally occur at low densities and only E. carlsbergi is known to form aggregations (Kozlov et al. 1990). Within the PFZ, prey may be more available, more abundant, or more predictable than in the cooler waters further south. If prey aggregate close to areas where steep temperature gradients occur, the use of foraging cues such as temperature may help diving predators reduce their search costs. This is consistent with the observed increase in fine-scale meandering behaviour of penguins within waters of 5.0 to $5.5^{\circ} \mathrm{C}$.

Both diving and flying predators might be expected to follow scale-dependent foraging strategies. However, for every unit of distance travelled, swimming is more energetically costly than flying or gliding (Maina 2000). Therefore, diving and flying predators may show different foraging trade-offs. For example, all other things being equal, diving predators might stay longer at a prey patch than do flying predators, if on average, it is more costly for them to travel to a new patch. Although scale-dependent strategies have been identified for flying seabirds (Weimerskirch 2007), it has hitherto been difficult to spatially or temporally resolve this for diving predators. With the advent of recently developed GPS technology, it is now possible to resolve this at much finer scales. Indeed, within the PFZ, we recorded some periods of fine-scale arearestricted foraging although foraging pathways generally remained direct.

FPT analysis shows that there were areas where birds focused their foraging effort, spending greater periods of time in a restricted locality (Fauchald \& Tveraa 2003). Foraging behaviour in these FPT hotspots may be anticipated to reflect greatly increased foraging effort. Indeed, we found a significantly greater number and depth of dives within FPT hotspots. However, when scaled by the duration of time that birds remained within a hotspot, the rates of diving showed no increase over those outside. Thus, the TDR data showed no apparent difference in the number of undulations per dive or in other dive characteristics that are often used to help establish behavioural differences. This suggests that further work is necessary to determine why penguins preferentially frequent these FPT hotspots, i.e. to establish whether the rate of penguin foraging efficiency (prey acquisition rate per dive) and/or prey quality (energetic density) are significantly greater in these areas. Such work is necessary since the cost of moving to other equally profitable locations may offset any potential gains, in which case it is likely that penguins are optimizing their effort in these locations.

The foraging behaviour of seabirds depends upon physical features at a variety of spatial and temporal scales. However, little is yet known about how pen- guins forage and detect prey. Charrassin \& Bost (2001) suggested that the depth of the surface mixed layer was crucial and that this generally governed prey availability for prey concentrated below the thermocline. If this is the case, then successful foraging is highly likely to be related to temperatures at the bottom of a dive as well as at the surface (Jouventin et al. 1994).

At locations within the PFZ where birds slow down, turn more frequently and spend long periods in spatially restricted foraging hotspots, it still remains uncertain whether the fine-scale movements actually reflect attempts to locate prey, responses resulting from actually having found prey, or random movements within a prey patch. Nonetheless, it is clearly evident from our results that birds significantly alter their behaviour in waters with a very specific surface temperature signal. This was previously only suspected but is now manifest in a variety of behavioural measures that can be more precisely measured with archival GPS loggers.

The importance of meso-scale structure in the foraging areas of king penguins has recently been highlighted by Cotté et al. (2007). These authors have shown that king penguins travelled directly towards foraging zones, where they altered their swimming speed in relation to meso-scale local oceanography. Our regression analyses highlight how travel speed can be modelled using other behavioural and environmental characteristics, indicating that travel speed is potentially a useful proxy for foraging behaviour. Similar foraging activity at the edge of eddies has been reported for other seabird species (Nel et al. 2001, Weimerskirch et al. 2004). This is thought to be due to the zones of convergence and divergence created by frontal eddies and meanders that concentrate zooplankton and micronekton (Pakhomov \& Fronemann 2000) and fish (Pakhomov et al. 1996). Thus, if prey are concentrated in areas with specific temperature gradients or specific water flow patterns, then locating prey may be more predictable in environmental space than in geographic space. Thus, in the open ocean, long commuting periods may be necessary for penguins to reach areas where cues relating to environmental factors make prey more predictable.

Our results show that the spatial information derived from conventional ARGOS telemetry can be used to describe many aspects of penguin foraging behaviour, including FPT and the degree of meandering in the foraging pathway. However, ARGOS positional information is insufficient to establish the precise location of periods of meandering or resolve the location of individual dives. Information from fast-response archival GPS loggers, collected at a much finer temporal and spatial resolution, allows these same aspects of forag- 
ing behaviour to be analysed much more accurately and more meaningfully in some cases.

In the marine environment where patchily distributed prey may be unpredictable at small spatial and temporal scales, measures of foraging behaviours (e.g. speed, dive depth, etc.) at fine resolution are now feasible using archival GPS loggers. This information will help reveal how a range of diving predators respond to an array of environmental cues and make foraging decisions at small spatial and temporal scales.

Acknowledgements. We thank A. Davies and A. Jones of Bangor University for technical assistance with producing the housings for the GPS loggers. This project was funded by the BAS DISCOVERY 2010 programme and by NERC grant NERC/D/S/1999/00078 to C.B.

\section{LITERATURE CITED}

Arhan M, Naveira-Garabato AC, Heywood KJ, Stevens DP (2002) The Antarctic Circumpolar Current between the Falkland Islands and South Georgia. J Phys Oceanogr 32:1914-1931

Benhamou S (2004) How to reliably estimate the tortuosity of an animal's path: straightness, sinuosity, or fractal dimension? J Theor Biol 229:209-220

Charrassin JB, Bost CA (2001) Utilization of the oceanic habitat by king penguins over the annual cycle. Mar Ecol Prog Ser 221:285-297

Charrassin JB, Park YH, Le Maho Y, Bost CA (2004) Fine resolution 3D temperature fields off Kerguelen from instrumented penguins. Deep-Sea Res I 51:2091-2103

Cotté C, Park YH, Guinet C, Bost CA (2007) Movements of foraging king penguins through marine mesoscale eddies. Proc R Soc Lond B Biol Sci 274:2385-2391

Fauchald P (1999) Foraging in a hierarchical patch system. Am Nat 153:603-613

- Fauchald P, Tveraa T (2003) Using first-passage time in the analysis of area-restricted search and habitat selection. Ecology 84:282-288

Fauchald P, Erikstad KE, Skarsfjord H (2000) Scale-dependent predator-prey interactions: the hierarchical spatial distribution of seabirds and prey. Ecology 81:773-783

Froget G, Butler PJ, Woakes AJ, Fahlman A, Kuntz G, Le Maho Y, Handrich Y (2004) Heart rate and energetics of free-ranging king penguins (Aptenodytes patagonicus). J Exp Biol 207:3917-3926

Hill SL, Reid K, Thorpe SE, Hinke J, Watters GM (2007) A compilation of parameters for ecosystem dynamics models of the Scotia Sea-Antarctic Peninsula region. CCAMLR Science 14:1-25

Jonsen ID, Myers RA, Flemming JM (2003) Robust statespace modeling of animal movement data. Ecology 84: 3055-3063

Jouventin P, Capdeville D, Cuenot-Chaillet R, Boiteau C (1994) Exploitation of pelagic resources by a non-flying seabird: satellite tracking of the king penguin throughout the breeding cycle. Mar Ecol Prog Ser 106:11-19

Kareiva P, Odell G (1987) Swarms of predators exhibit 'prey taxis' if individual predators use area-restricted search. Am Nat 130:233-270

Kooyman GL, Davis RW (1987) Diving behaviour and performance with special reference to penguins. In: Croxall JP (ed) Seabirds feeding ecology and role in marine ecosys- tems. Cambridge University Press, Cambridge, p 63-75

Kozlov AN, Shust KV, Zemsky AV (1990) Seasonal and interannual variability in the distribution of Electrona carlsbergi in the Southern Polar Front area (the area to the north of South Georgia is used as an example). Convention on the Conservation of Antarctic Marine Living Resources Selected Scientific Papers 7:337-367

Maina JN (2000) What it takes to fly: the structural and functional respiratory refinements in birds and bats. J Exp Biol 203:3045-3064

Nel DC, Lutjeharms JRE, Pakhomov EA, Ansorge IJ, Ryan PG, Klages NTW (2001) Exploitation of mesoscale oceanographic features by grey-headed albatross Thalassarche chrysostoma in the Southern Indian Ocean. Mar Ecol Prog Ser 217:15-26

Olsson O, North AW (1997) Diet of the king penguin Aptenodytes patagonicus during three summers at South Georgia. Ibis 139:504-512

Orsi AH, Whitworth T III, Nowlin WD Jr (1995) On the meridional extent of the Antarctic Circumpolar Front. Deep-Sea Res 42:641-673

> Pakhomov EA, Fronemann PW (2000) Composition and spatial variability of macrozooplankton and micronekton within the Antarctic Polar Frontal Zone of the Indian Ocean during austral summer 1997. Polar Biol 23:410-419

Pakhomov EA, Perissinotto R, McQuaid CD (1996) Prey composition and daily rations of myctophid fishes in the Southern Ocean. Mar Ecol Prog Ser 134:1-14

> Petersen S, Ryan PG, Gremillet D (2006) Is food availability limiting African penguins Spheniscus demersus at Boulders? A comparison of foraging effort at mainland and island colonies. Ibis 148:14-26

Pinaud D, Weimerskirch H (2005) Scale-dependent habitat use in a long-ranging central place predator. J Anim Ecol 74:852-863

Pütz K, Wilson RP, Charrassin JB, Raclot T and others (1998) Foraging strategy of king penguins (Aptenodytes patagonicus) during summer at the Crozet Islands. Ecology 79:1905-1921

Saunders S (ed) (2006) Important bird areas in the UK's overseas territories. RSPB, Sandy

Schofield G, Bishop CM, MacLean G, Brown P and others (2007) Novel GPS tracking of sea turtles as a tool for conservation management. J Exp Mar Biol Ecol 347:58-68

Sokolov S, Rintoul SR, Wienecke B (2006) Tracking the Polar Front south of New Zealand using penguin dive data. Deep-Sea Res I 53:591-607

Trathan PN, Brandon MA, Murphy EJ (1997) Characterization of the Antarctic Polar Frontal Zone to the north of South Georgia in summer 1994. J Geophys Res C 102: 10483-10497

Viswanathan GM, Afanasyev V, Buldyrev SV, Murphy EJ, Prince PA, Stanley HE (1996) Levy flight search patterns of wandering albatrosses. Nature 381:413-415

Weimerskirch H (2007) Are seabirds foraging for unpredictable resources? Deep-Sea Res II 54:211-223

> Weimerskirch $\mathrm{H}$, Bonadonna $\mathrm{F}$, Bailleul $\mathrm{F}$, Mabille $\mathrm{G}$, Dell'Omo G, Lipp HP (2002) GPS tracking of foraging albatrosses. Science 295:1259

Weimerskirch H, Le Corre M, Jacquemet S, Potier M, Marsac DP (2004) Foraging strategy of a top predator in tropical waters: great frigatebirds in the Mozambique Channel. Mar Ecol Prog Ser 275:297-308

Wilson RP, Pütz K, Peters G, Culik B, Scolaro JA, Charrassin JB, Ropert-Coudert Y (1997) Long-term attachment of transmitting and recording devices to penguins and other seabirds. Wildl Soc Bull 25:101-106 